\title{
ANALISIS USABILITAS WEBSITE SIAM UMRI MENGGUNAKAN METODE USABILITY TESTING
}

\author{
Faradila Ananda Yul, Miftahul Jannah \\ Program Studi Teknik Industri, Fakultas Teknik, Universitas Muhammadiyah Riau \\ Jalan Tuanku Tambusai Ujung, Kecamatan Tampan, Kelurahan Delima, Kota Pekanbaru, Riau \\ 28291 \\ E-mail: faradila@umri.ac.id
}

\begin{abstract}
The thing that underlies the existence of a website is the development of information and communication technology. This study aims to measure the Usability level of the Student Academic Information System (SIAM) Website at Universitas Muhammadiyah Riau. Some problems encountered were that there was no reusability evaluation of the UMRI SIAM website, as well as complaints from UMRI students when accessing the website. The reusability problem in this study was resolved by conducting usability testing with five dimensions proposed by Nielsen (1993), namely learnability, efficiency, memorability, error \& user satisfaction when accessing the SIAM UMRI website and using the thinking aloud method which required 3-5 respondents. The subjects studied were expert users (UMRI students) and novice users (nonUMRI students). Based on the results of the analysis on the learnability dimension, it is found that the respondents have the ability to learn a good website. In the efficiency dimension, the results of the increase in the speed of completing tasks by the respondents are obtained. Furthermore, in the memorability dimension, the results show that the respondents have good memory ability. In the error dimension, there are 38 problems when accessing the SIAM UMRI website, and in the satisfaction dimension, the results of respondents' satisfaction when accessing the SIAM UMRI website are obtained with a score of 70. In addition, in this study there are recommendations for improving the SIAM UMRI website.
\end{abstract}

Keywords: $\quad$ Expert User, Novice User, Thinking Aloud, Usability, Website of SIAM UMRI.

\begin{abstract}
Abstrak
Hal yang mendasari adanya website adalah karena adanya perkembangan teknologi informasi dan komunikasi. Penelitian ini bertujuan untuk mengukur tingkat Usabilitas Website Sistem Informasi Akademik Mahasiswa (SIAM) di Universitas Muhammadiyah Riau. Permasalahan yang ditemui adalah belum dilakukannya evaluasi usabilitas terhadap website SIAM UMRI, serta keluhan mahasiswa UMRI saat mengakses website tersebut. Permasalahan usabilitas dalam penelitian ini diselesaikan dengan melakukan usability testing dengan lima dimensi yang dikemukakan oleh Nielsen (1993) yakni learnability, efficiency, memorability, error \& satisfaction pengguna saat mengakses website SIAM UMRI serta menggunakan metode thinking aloud yang membutuhkan responden $3-5$ orang. Subjek yang diteliti merupakan expert user (mahasiswa UMRI) serta novice user (mahasiswa non UMRI). Berdasarkan hasil analisa pada dimensi learnability didapatkan hasil bahwa responden memiliki kemampuan mempelajari website yang baik. Pada dimensi efficiency didapatkan hasil peningkatan kecepatan penyelesaian task oleh responden. Selanjutnya pada dimensi memorability didapatkan hasil bahwa responden memiliki kemampuan mengingat yang baik. Dalam dimensi error didapatkan 38 permasalahan saat mengakses website SIAM UMRI, serta pada dimensi satisfaction didapatkan hasil kepuasan responden saat mengakses website SIAM UMRI dengan score 70. Selain itu dalam penelitian ini terdapat rekomendasi untuk perbaikan website SIAM UMRI.
\end{abstract}

Kata Kunci: $\quad$ Pengguna Ahli, Pengguna Pemula, Thinking Aloud, Usability, Website SIAM UMRI.

\section{Pendahuluan}

Penerapan teknologi informasi khususnya internet, membuat proses penyebaran informasi dan komunikasi menjadi lebih cepat, mudah dan 
murah, serta tanpa batasan jarak dan waktu. Karena adanya perkembangan teknologi informasi dan komunikasi tercipta suatu jaringan antar komputer yang saling berkaitan disebut website.

Website merupakan kumpulan halaman halaman website, yang biasanya terangkum dalam sebuah domain atau subdomain, yang tempatnya berada dalam World Wide Web (www) di internet [24]. Website merupakan kumpulan dari halaman web yang sudah di publikasikan dijaringan internet dan memiliki domain / URL (uniform Resource Locator) yang dapat diakses pengguna internet dengan mengetikan alamatnya. [1].

Dalam penggunaannya website dapat diaplikasikan pada instansi perguruan tinggi/ universitas yang mana sebagai tolak ukur kualitas. Website suatu universitas merupakan representative / citra sebuah universitas di dunia maya. Pada interaksi pertama, masyarakat secara luas baik tingkat lokal maupun internasional akan melihat tampilan website tersebut. Dalam pemahamannya website perlu memiliki dan menyediakan usabilitas yang baik sehingga interaksi dari para pembelajar dapat senatural dan sespontan mungkin [25]. Usability merupakan kombinasi dari tiga kata guna yang mengandung makna yang berbeda pula antara lain yaitu yang pertama ada berguna (useful), sistem yang berfungsi seperti yang diinginkan oleh penggunanya. Kata kedua yaitu dapat digunakan (usable) yang berarti sistem mudah dioperasikan.kata kombinasi ketiga yaitu digunakan (used) sistem dapat memotivasi penggunanya untuk menggunakannya, menarik, menyenangkan dan hal lainnya [24].

Tujuan utama usability digunakan adalah untuk mudah dipelajari bagi user saat pertama kali menggunakannya, efektif dan efisien pada saat digunakan, aman saat menggunakannya, punya utility yang tinggi, mudah diingat cara menggunakannya. Semua publikasi dari websitewebsite tersebut dapat membentuk sebuah jaringan informasi yang sangat besar. Web page layaknya sebuah buku yang dapat menampung berbagai informasi tentang banyak hal baik bersifat komersil maupun non komersil. Melalui media web inilah seseorang dapat memberikan informasi tertentu kepada orang lain yang berada di seluruh dunia. Hal - hal yang diuji pada usabilitas website adalah : jenis interaksi pengguna dengan interface, performansi pengguna, waktu yang digunakan untuk menyelesaikan tugas serta kepuasan dari pengguna ketika menggunakan sistem beberapa data kuantitatif dan kualitatif, dimana data - data tersebut kemudian dikumpulkan dan dianalisis.

Secara sekilas, Universitas Muhammadiyah Riau memiliki berbagai media penyampaian informasi seperti website. Website Sistem Informasi Akademik Mahasiswa Universitas Muhammadiyah Riau (SIAM UMRI) merupakan sebuah penerapan dari pemanfaaatan internet berbasis web dalam bidang akademik. Penelitian ini dilakukan untuk menganalisa permasalahan, efisiensi, efektivitas serta kepuasan pengguna terhadap website SIAM UMRI sehingga, bisa menjadi masukan bagi pihak pengembang website tersebut untuk perbaikan dan pengembangan website SIAM UMRI, serta memudahkan pengguna menggunakan website SIAM UMRI.

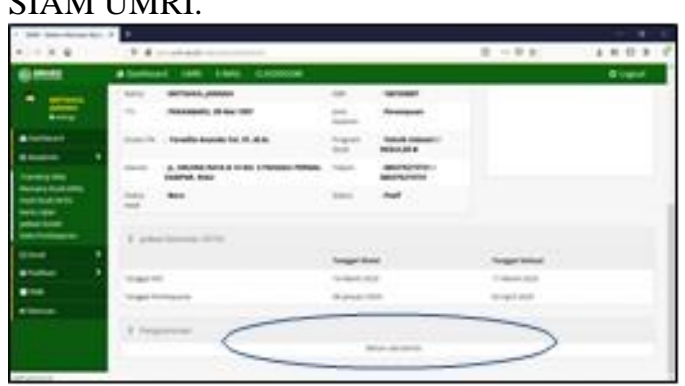

Gambar 1. Menu Pengumuman yang Tidak Menampilkan Informasi Terupdate

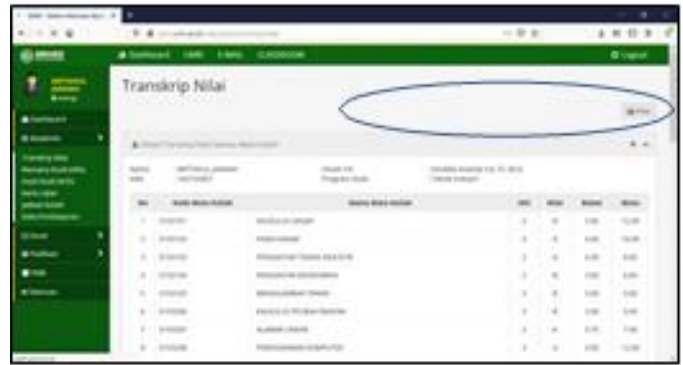

Gambar 2. Tidak Ada Menu Download Berkas

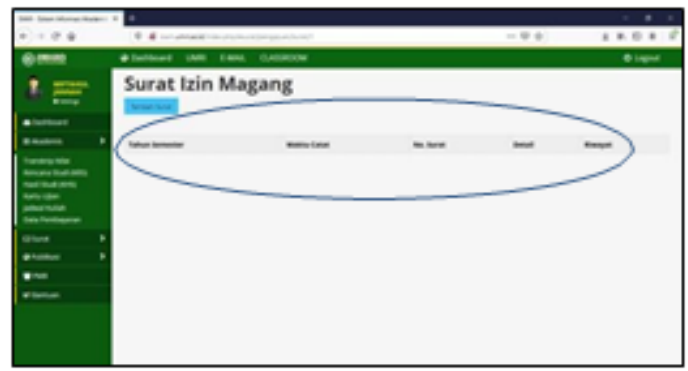

Gambar 3. Menu Surat Izin Magang Tidak Menampilkan History Magang Mahasiswa 


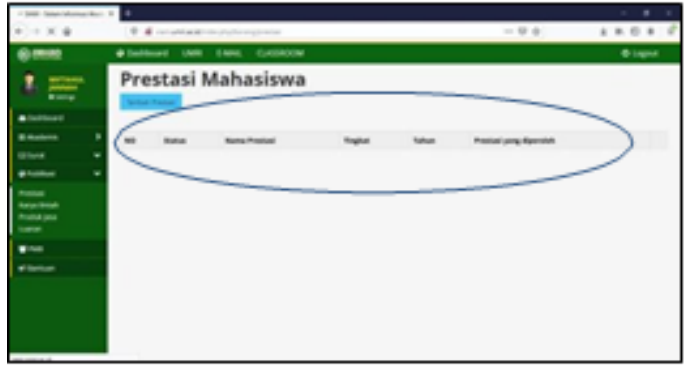

Gambar 4. Menu Prestasi Mahasiswa Tidak Menampilkan History Prestasi Mahasiswa

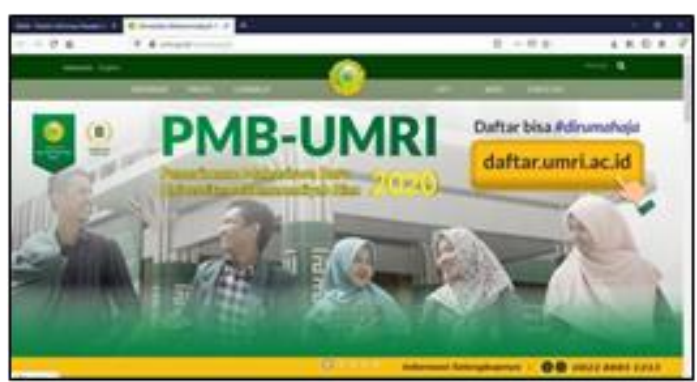

Gambar 5. Tampilan Fitur Bantuan Siam Umri Persis Tampilan Website Umri, Tidak Ada Bedanya

Sebelum melakukan penelitian, peneliti melakukan wawancara awal terhadap 32 responden dalam hal ini mahasiswa Universitas Muhammadiyah Riau untuk mengetahui keluhan apa saja yang didapati oleh mahasiswa saat mengakses website SIAM UMRI. Adapun keluhan yang didapat adalah : website kurang fleksibel saat mendownload berkas (transkip nilai, hasil studi, dsb), pengguna belum paham cara untuk menyimpan berkas ke dalam bentuk pdf melalui browser, website sering error \& lambat, kuesioner pada website harap dikurangi / dihilangkan saja, sistem pada website tidak update secara real time, tampilan website SIAM UMRI masih kurang menarik, website SIAM UMRI perlu diberikan menu notifikasi atau reminder ke mahasiswa/i secara personal guna mendapatkan info terupdate, serta tidak adanya kontak dosen setiap prodi di SIAM guna membantu mahasiswa saat menghubungi dosen terkait.

Dengan tampilan website SIAM UMRI saat ini serta ulasan singkat dari responden mengenai kondisi website SIAM UMRI, mendorong dilakukannya sebuah penelitian untuk mengukur dan melihat sejauh mana usability sebuah sistem yang telah digunakan sehingga kedepannya sebuah sistem menjadi lebih baik serta berdaya guna tinggi. Oleh karenanya peneliti akan membuat studi kasus dari website Sistem Informasi Akademik Mahasiswa (SIAM UMRI) menggunakan metode Usability Testing dan Thinking Aloud.

\section{Metodologi}

\section{Flowchat Penelitian}

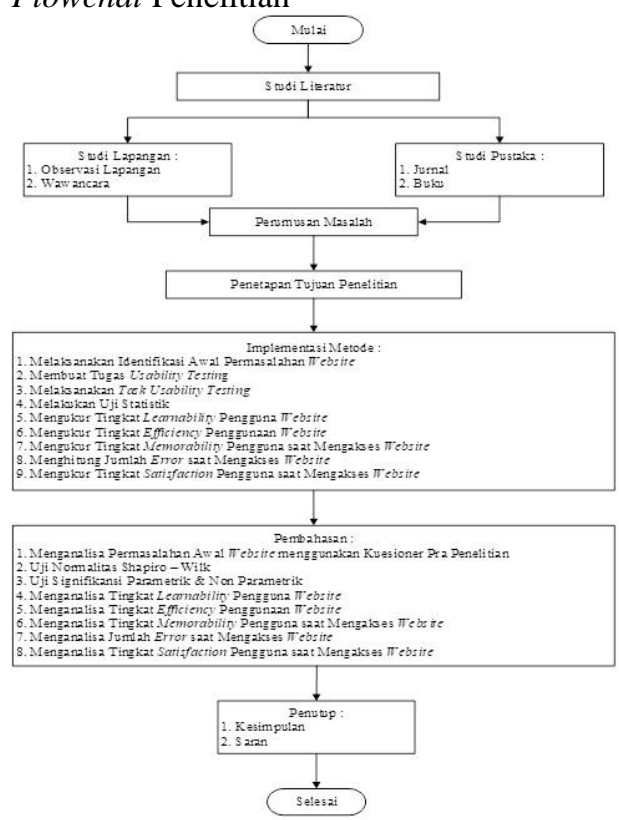

Gambar 6. Flowchart Penelitian

Studi Pendahuluan

Studi pendahuluan dilakukan dengan dua tahap yaitu studi literatur dan pengamatan objek website SIAM UMRI. Tahapan studi pendahuluan ini dilakukan untuk mengetahui permasalahan yang ada di website SIAM UMRI tersebut. Adapun cara melakukan studi pendahuluan yaitu:

1. Pengenalan terhadap objek penelitian dengan cara membuka serta menelusuri setiap fitur dari website tersebut.

2. Untuk menentukan topik permasalahan yang akan di teliti nantinya, maka dilakukan dengan cara mendalami teori-teori yang berkaitan dengan topik penelitian.

3. Data yang diperlukan untuk penelitian awal ini, didapatkan dengan penyebaran kuesioner pra penelitian kepada 32 responden mahasiswa UMRI. Hal ini dilakukan untuk mengetahui sejauh mana mahasiswa UMRI mengetahui website SIAM UMRI.

\section{Studi Literatur}

Studi literatur digunakan sebagai landasan logika berpikir dalam penyelesaian masalah secara ilmiah. Pada dasarnya bobot atau nilai suatu penelitian ditentukan oleh seberapa cermat 
landasan teori yang dipakai oleh peneliti. Studi literatur yang akan dikumpulkan seperti:

1. Laporan-laporan yang berkaitan dengan penelitian ini.

2. Membaca buku-buku yang berkaitan dengan Ergonomi Usability, HCI, Thinking Aloud, Statistik, User Interface, dan lain-lain.

3. Membaca buku-buku serta referensi umum yang berhubungan dengan penelitian ini.

Studi Objek yang Diamati

Studi objek yang diamati adalah website SIAM UMRI. Studi objek dilakukan untuk mengetahui sistem yang bekerja dan kegunaan dari website tersebut. Pengenalan terhadap objek penelitian dilakukan dengan cara membuka serta menelusuri setiap fitur dari website tersebut. Data yang diperoleh dari pengamatan objek yaitu berupa fitur yang tidak terdapat dari dalam website tersebut.

\section{Identifikasi Masalah}

Setelah studi pendahuluan yang berisikan studi literatur dan studi objek yang diamati telah dilakukan, langkah selanjutnya adalah mengidentifikasi masalah yang ada pada website SIAM UMRI yang nantinya akan dijadikan sebagai objek fokus penelitian. Dengan tahapan mengidentifikasi masalah, diketahui bahwa penyebab permasalahan yang ada yaitu belum dilakukannya pengukuran usability pada website SIAM UMRI, serta terdapat keluhan pengguna saat mengakses website SIAM UMRI.

Perumusan Masalah

Penentuan rumusan masalah bertujuan untuk memperjelas masalah yang akan di teliti nantinya. Rumusan masalah merupakan suatu pertanyaan yang akan di cari jawabannya melalui pengumpulan dan pengolahan data. Dilihat dari observasi awal diketahui bahwa tingkat kenyamanan pengguna tergolong rendah karena belum adanya evaluasi tentang usability pada website tersebut. Dari permasalahan tersebut, maka rumusan masalah dalam penelitian ini adalah bagaimanakah tingkat usabilitas website SIAM UMRI dengan lima dimensi yang dikemukakan oleh Nielsen (1993) yakni learnability, efficiency, memorability, error \& satisfaction pengguna saat mengakses website SIAM UMRI serta rekomendasi yang dapat diberikan untuk menyelesaikan permasalahan yang ditemui pengguna saat mengakses website SIAM UMRI.
Penetapan Tujuan

Penelitian yang baik harus memiliki tujuan yang jelas, nyata dan terukur. Penetapan tujuan merupakan tahapan untuk menggambarkan yang ingin dicapai oleh peneliti setelah laporan penelitian selesai.

Jenis Data

Jenis data yang digunakan dalam pengumpulan data ini adalah jenis data primer dan data sekunder.

1. Data Primer.

Data primer adalah data yang diperoleh dari instansi yaitu fitur SIAM UMRI, penyebaran kuesioner pra penelitian untuk mengidentifikasi sudut pandang pengguna (mahasiswa UMRI) dalam menggunakan website SIAM UMRI. Selanjutnya adalah capture task yang diberikan kepada responden ketika melakukan usability testing.

2. Data Sekunder.

Data sekunder merupakan data yang secara tidak langsung berhubungan dengan masalah yang diteliti, misalnya data yang diperoleh dari literatur, dokumentasi perusahaan, hasil penelitian sebelumnya, dan data lainnya. Dari hasil pengumpulan data yang telah dilakukan, akan dilanjutkan dengan proses pengolahan data.

Implementasi Metode

Pada tahap implementasi metode ini, dilakukan penerapan metode thinking aloud dan usability testing dengan melakukan langkah langkah sebagai berikut :

1. Melaksanakan identifikasi awal permasalahan website.

2. Membuat tugas usability testing.

3. Melaksanakan task usability testing.

4. Melakukan uji statistik.

5. Mengukur tingkat learnability pengguna website.

6. Mengukur tingkat efficiency penggunaan website.

7. Mengukur tingkat memorability pengguna saat mengakses website SIAM UMRI.

8. Menghitung jumlah error saat mengakses website SIAM UMRI.

9. Menghitung jumlah error saat mengakses website SIAM UMRI.

\section{Hasil dan Pembahasan}

Identifikasi Permasalahan Awal Website SIAM UMRI 
Dari tahap pra penelitian tersebut, peneliti mengajukan pertanyaan kepada responden sebanyak 5 pertanyaan, dengan total responden sebanyak 32 orang. Berikut merupakan gambaran umum mengenai website SIAM UMRI yang telah dirangkum :

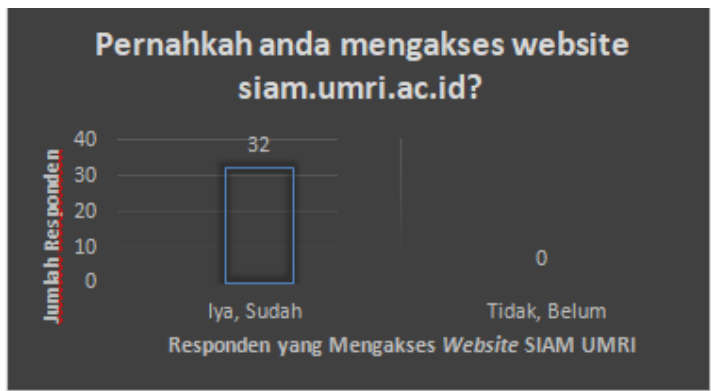

Gambar 7. Mahasiswa UMRI yang telah / belum mengakses website SIAM UMRI

Dari data yang didapat, sebanyak 32 responden pernah mengakses website SIAM UMRI.

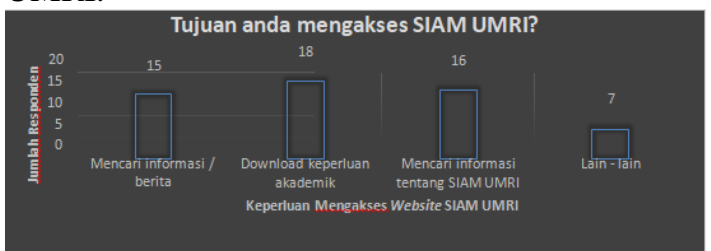

Gambar 8. Tujuan mengakses website SIAM UMRI

Dari data yang didapat, tujuan mahasiswa mengakses website SIAM UMRI sebanyak 15 responden adalah untuk mencari informasi / berita, 18 responden untuk mendownload keperluan akademik, 16 responden untuk mencari informasi tentang SIAM UMRI, dan 7 responden mengakses selain hal-hal diatas.

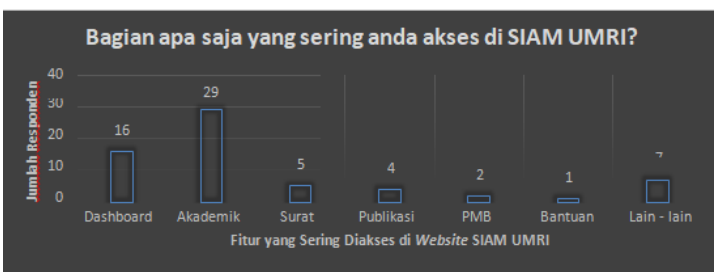

Gambar 9. Bagian yang sering diakses di Website SIAM UMRI

Dari data yang didapat, bagian yang sering diakses mahasiswa di website SIAM UMRI adalah sebanyak 16 responden sering mengakses menu dashboard, 29 responden sering mengakses menu akademik, 5 responden sering mengakses menu surat, 4 responden sering mengakses menu publikasi, 2 responden sering mengakses menu PMB (Penerimaan Mahasiswa Baru), 1 responden sering mengakses menu bantuan, serta 7 responden sering mengakses menu selain yang disebutkan di atas.

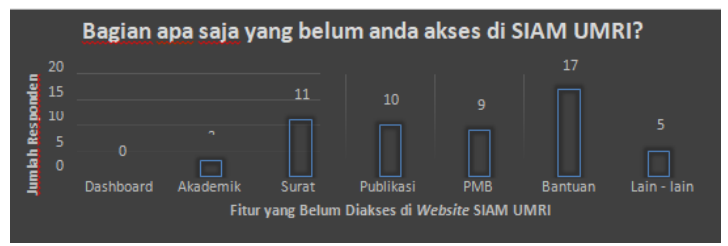

Gambar 10. Bagian yang belum diakses di Website SIAM UMRI

Dari data yang didapat, bagian yang belum diakses mahasiswa di website SIAM UMRI adalah sebanyak 0 responden belum pernah mengakses menu dashboard, 3 responden belum pernah mengakses menu akademik, 11 responden belum pernah mengakses menu surat, 10 responden belum pernah mengakses menu PMB (Penerimaan Mahasiswa Baru), 17 responden belum pernah mengakses menu bantuan, serta 5 responden belum pernah mengakses menu selain yang disebutkan di atas.

\section{Uji Statistik}

Uji statistik yang digunakan dalam penelitian ini adalah uji normalitas dengan menggunakan uji Shapiro-Wilk karena jumlah data dibawah 50 dan uji hipotesis beda dua mean dependen non parametrik menggunakan sign test.

\section{Uji Statistik Expert User}

Hipotesis statistik yang ditentukan untuk uji normalitas pada penelitian usabilitas website SIAM UMRI dengan responden expert user ini memiliki tingkat signifikansi $(\alpha)$ sebesar 0,05 sesuai dengan persamaan 5.1 berikut :

H0 : Data terdistribusi normal

H1 : Data tidak terdistribusi normal

H0 ditolak jika nilai Wilk hitung < Wilk tabel

Wilk tabel $(n=5)=0,762$

Hipotesis statistik untuk sign test memiliki tingkat signifikansi $(\alpha)$ sebesar

0,05 seperti pada persamaan 5.2 berikut :

$\mathrm{H} 0: \mu 1=\mu 2$

Tidak ada perbedaan signifikan pada jumlah pengerjaan yang berhasil diselesaikan expert user pada waktu pengulangan ke 1 dengan 2, 2 dengan 3 , dan 1 dengan 3 
$\mathrm{H} 1: \mu 1 \neq \mu 2$

Ada perbedaan signifikan pada jumlah pengerjaan yang berhasil diselesaikan pada expert user pada waktu pengulangan ke 1 dengan 2, 2 dengan 3, dan 1 dengan 3.

Dasar pengambilan keputusan keputusan dalam uji Wilcoxon :

1. Jika nilai Asygmp.Sig. (2 - tailed) lebih kecil dari <0.05, maka H1 diterima

2. Sebaliknya, jika nilai Asygmp.Sig. (2 - tailed) lebih besar dari >0.05, maka H1 ditolak (5.2)

\section{Uji Statistik Novice User}

Hipotesis statistik yang ditentukan untuk uji normalitas pada penelitian usabilitas website SIAM UMRI dengan responden novice user ini memiliki tingkat signifikansi $(\alpha)$ sebesar 0,05 sesuai dengan persamaan 5.1 berikut :

H0 : Data terdistribusi normal

H1 : Data tidak terdistribusi normal

H0 ditolak jika nilai Wilk hitung < Wilk tabel

Wilk tabel $(\mathrm{n}=5)=0,762$

Hipotesis statistik untuk sign test memiliki tingkat signifikansi $(\alpha)$ sebesar 0,05 seperti pada persamaan 5.2 berikut :

$\mathrm{H} 0: \mu 1=\mu 2$

Tidak ada perbedaan signifikan pada jumlah pengerjaan yang berhasil diselesaikan novice user pada waktu pengulangan ke 1 dengan 2, dan 1 dengan 3

H1 : $\mu 1 \neq \mu 2$

Ada perbedaan signifikan pada jumlah pengerjaan yang berhasil diselesaikan pada novice user pada waktu pengulangan ke 1 dengan 2, dan 1 dengan 3. Dasar pengambilan keputusan keputusan dalam uji Wilcoxon :

1. Jika nilai Asygmp.Sig. (2 - tailed) lebih kecil dari $<0.05$, maka $\mathrm{H} 1$ diterima

2. Sebaliknya, jika nilai Asygmp.Sig. (2 - tailed) lebih besar dari $>0.05$, maka

H1 ditolak (5.2)

Hipotesis statistik untuk paired $\mathrm{T}-$ test ini memiliki tingkat signifikansi $(\alpha)$ sebesar 0,05 seperti pada persamaan 5.3 berikut .

$\mathrm{H} 0: \mu 1=\mu 2$

Tidak ada perbedaan signifikan pada jumlah pengerjaan yang berhasil diselesaikan novice user pada waktu pengulangan ke 2 dengan 3.

$\mathrm{H} 1: \mu 1 \neq \mu 2$
Ada perbedaan signifikan pada jumlah pengerjaan yang berhasil diselesaikan novice user pada waktu pengulangan ke 2 dengan 3 . Dasar pengambilan keputusan keputusan dalam uji Paired T - Test :

1. Jika nilai $\mathrm{t}$ hitung $>\mathrm{t}$ tabel, maka $\mathrm{H} 0$ ditolak dan H1 diterima

2. Sebaliknya, jika nilai $\mathrm{t}$ hitung $<\mathrm{t}$ tabel, maka $\mathrm{H} 0$ diterima dan $\mathrm{H} 1$ ditolak (5.3)

Uji Normalitas Shapiro - Wilk

Uji Normalitas Shapiro - Wilk Expert User

Tabel 1. Hasil Uji Normalitas Expert User

\begin{tabular}{|c|c|c|c|c|c|}
\hline \multirow{2}{*}{$\begin{array}{c}\text { Jumlah } \\
\text { responden }\end{array}$} & $\begin{array}{c}\text { Waktu } \\
\text { pengulangan }\end{array}$ & \multirow{2}{*}{$\begin{array}{c}\text { Wilk } \\
\text { tabel }\end{array}$} & Wilk hitung & \multicolumn{2}{|c|}{$\begin{array}{c}\text { Terdistribusi } \\
\text { Normal }\end{array}$} \\
\cline { 5 - 7 } & & & & Ya & Tidak \\
\hline \multirow{3}{*}{5} & 1 & 0.762 & 0.178 & & $\sqrt{ }$ \\
\cline { 2 - 6 } & 2 & 0.762 & 0.942 & $\sqrt{ }$ & \\
\cline { 2 - 6 } & 3 & 0.762 & 0.722 & & $\sqrt{ }$ \\
\hline
\end{tabular}

Uji Normalitas Shapiro - Wilk Novice User

Pada uji normalitas sesuai dengan Tabel 1, data menunjukkan bahwa jumlah pengerjaan oleh novice user di waktu pengulangan 1 nilai wilk hitung sebesar 0,342 dimana lebih kecil dari nilai wilk tabel sebesar 0,762, sehingga data dikatakan tidak normal. Pada waktu pengulangan 2, nilai wilk hitung sebesar 0,836 dimana lebih besar dari nilai wilk tabel sebesar 0,762, sehingga data dikatakan normal. Selanjutnya pada waktu pengulangan 3 , nilai wilk hitung sebesar 0,828 dimana lebih besar dari nilai wilk tabel sebesar 0,762, sehingga data dikatakan normal.

Tabel 2. Hasil Uji Normalitas Novice User

\begin{tabular}{|c|c|c|c|c|c|}
\hline \multirow{2}{*}{$\begin{array}{c}\text { Jumlah } \\
\text { responden }\end{array}$} & $\begin{array}{c}\text { Waktu } \\
\text { pengulangan }\end{array}$ & \multirow{2}{*}{$\begin{array}{c}\text { Wilk } \\
\text { tabel }\end{array}$} & Wilk hitung & \multicolumn{2}{|c|}{$\begin{array}{c}\text { Terdistribusi } \\
\text { Normal }\end{array}$} \\
\cline { 5 - 7 } & & & Ya & Tidak \\
\hline \multirow{3}{*}{5} & 1 & 0.762 & 0.342 & & $\sqrt{ }$ \\
\cline { 2 - 6 } & 2 & 0.762 & 0.836 & $\sqrt{ }$ & \\
\cline { 2 - 6 } & 3 & 0.762 & 0.828 & $\sqrt{ }$ & \\
\hline
\end{tabular}

Uji Signifikansi Sign Test \& Paired T-Test

Uji Signifikansi Expert User

Selanjutnya yaitu uji signifikansi pada setiap pasangan waktu pengulangan yang dilakukan expert user menggunakan metode nonparametrik. Uji non parametrik dilakukan dengan sign test dilakukan terhadap data yang tidak normal yakni pasangan data jumlah pengerjaan oleh expert user pada waktu pengulangan 1 dengan waktu pengulangan 2, pasangan data jumlah pengerjaan oleh expert user pada waktu pengulangan 2 dan waktu 
pengulangan 3, serta pasangan data jumlah pengerjaan oleh expert user pada waktu pengulangan 1 dan waktu pengulangan 3 . Tabel 5.4 menunjukkan hasil perhitungan uji signifikansi dengan sign test dari waktu pengerjaan yang dilakukan oleh expert user.

Tabel 3. Hasil Uji Signifikansi Perbedaan Jumlah Pengerjaan pada Setiap Waktu Pengulangan Expert User

\begin{tabular}{|c|c|c|c|c|c|c|}
\hline \multirow[t]{2}{*}{ Perbandingan } & \multirow[t]{2}{*}{ Hipotes is } & \multirow[t]{2}{*}{ Keputus an } & \multirow[t]{2}{*}{ r Tabel } & \multirow[t]{2}{*}{ r Hitung } & \multicolumn{2}{|c|}{$\begin{array}{c}\text { Berbeda } \\
\text { signifikan? }\end{array}$} \\
\hline & & & & & Ya & Tidak \\
\hline $\begin{array}{l}\text { E pengerjan pada } \\
\text { wakktu pengulangan } 1 \\
\text { dan } 2\end{array}$ & $\begin{array}{l}\mathrm{H} 0 \\
\mu \sum \text { pada waktu } 1= \\
\mu \sum \text {. pada wakktu } 2 \\
\mathrm{H} 1 \\
\mu \sum \text { pada wakktu } 1 \neq \\
\mu \sum \text { pada waktu } 2\end{array}$ & Tolak HO & 0.7545 & 0.043 & $\sqrt{ }$ & \\
\hline
\end{tabular}

Tabel 4. Hasil Uji Signifikansi Perbedaan Jumlah Pengerjaan pada Setiap Waktu Pengulangan Expert User (lanjutan)

\begin{tabular}{|c|c|c|c|c|c|c|}
\hline \multirow[t]{2}{*}{ Perbandingan } & \multirow[t]{2}{*}{ Hipotes is } & \multirow[t]{2}{*}{ Keputus an } & \multirow[t]{2}{*}{ r Tabel } & \multirow[t]{2}{*}{ r Hitung } & \multicolumn{2}{|c|}{$\begin{array}{c}\text { Berbeda } \\
\text { signifikan? }\end{array}$} \\
\hline & & & & & Ya & Tidak \\
\hline \multirow{2}{*}{$\begin{array}{l}\text { | pengerjaan pada } \\
\text { wakktu pengulangan } 1 \\
\text { dan } 3\end{array}$} & $\begin{array}{l}H 0 \\
: \mu \sum \text { pada waktu } 1= \\
\mu \Sigma \text {. pada waktu } 3\end{array}$ & \multirow[t]{2}{*}{ Tolak Ho } & \multirow{2}{*}{0.7545} & \multirow{2}{*}{0.043} & \multirow[t]{2}{*}{$\checkmark$} & \\
\hline & $\begin{array}{l}: 11 \\
: \mu \sum \text { pada wakktu } 1 \neq \\
u<\text { pada waktu } 3\end{array}$ & & & & & \\
\hline \multirow{2}{*}{ 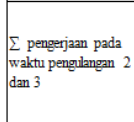 } & $\begin{array}{l}\mid 10 \\
: \mu \sum \text { pada wakktu } 2= \\
\mu \Gamma \text { pada waktu } 3\end{array}$ & \multirow[b]{2}{*}{ Tolak HO } & \multirow[b]{2}{*}{0.7545} & \multirow[b]{2}{*}{0.345} & \multirow[b]{2}{*}{$\checkmark$} & \\
\hline & $\begin{array}{l}\text { H1 } \\
: \mu \sum \text { pada waktu } 2 \neq \\
\mu \sum \text { pada waktu } 3\end{array}$ & & & & & \\
\hline
\end{tabular}

Dari Tabel 3 \& 4 dapat dilihat bahwa nilai $r$ hitung pada perbandingan jumlah pengerjaan oleh expert user di waktu pengulangan 1 dan 2 , waktu pengulangan 2 dan 3 , serta waktu pengulangan 1 dan 3 memiliki nilai lebih kecil dari $r$ tabel, sehingga dapat disimpulkan bahwa terdapat perbedaan signifikan antara jumlah pengerjaan yang berhasil expert user selesaikan pada waktu pengulangan 1 dan 2, 2 dan 3 serta 1 dan 3.

Uji Signifikansi Novice User

Tabel 5. Hasil Uji Signifikansi Perbedaan Jumlah Pengerjaan pada Setiap Waktu Pengulangan Novice User

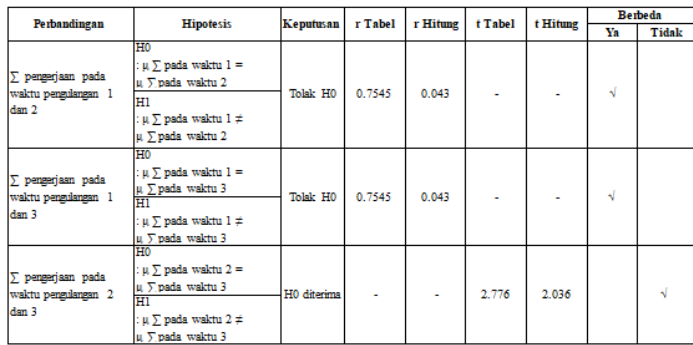

Dari Tabel 5. dapat dilihat bahwa nilai $r$ hitung pada perbandingan jumlah pengerjaan oleh novice user di waktu pengulangan 1 dan 2 , dan waktu pengulangan 1 dan 3 memiliki nilai lebih kecil dari $r$ tabel, sehingga dapat disimpulkan bahwa terdapat perbedaan signifikan antara jumlah pengerjaan yang berhasil novice user selesaikan pada waktu pengulangan 1 dan 2 , serta 1 dan 3 . Selanjutnya di waktu pengulangan 2 dan 3 memiliki nilai $t$ hitung lebih kecil dari t tabel, sehingga dapat disimpulkan bahwa tidak terdapat perbedaan signifikan antara jumlah pengerjaan yang berhasil novice user selesaikan pada waktu pengulangan 2 dan 3 .

\section{Pengerjaan Task}

Setelah responden mengerjakan task sesuai dengan skenario yang diberikan serta waktu pengujian yang dibatasi selama 1-30 menit dengan pengulangan sebanyak $3 \mathrm{kali}$, diperoleh data jumlah waktu pengerjaan task responden saat mengakses website SIAM UMRI pada setiap waktu pengulangannya. Data ringkasan hasil pengerjaan task berupa total waktu pengerjaan task yang berhasil diselesaikan pada setiap waktu pengulangan oleh expert user serta novice user yang ditunjukkan.

\section{Task oleh Expert User}

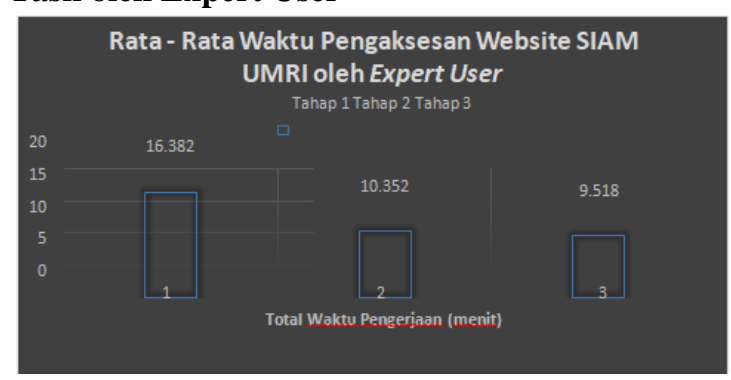

Gambar 11. Rata-Rata Waktu Pengerjaan Task oleh Expert User

Task oleh Novice User 


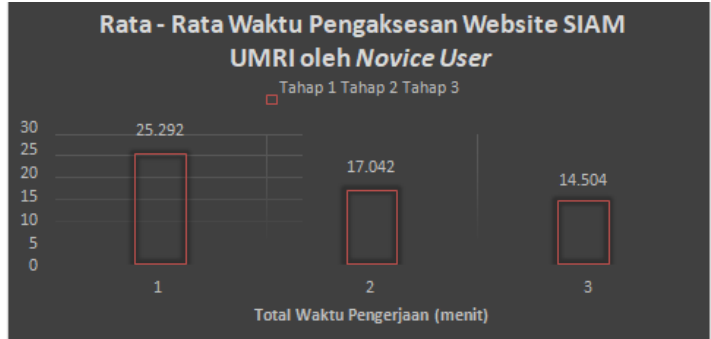

Gambar 12. Rata-Rata Waktu Pengerjaan Task oleh Novice User

\section{Learnability Expert User}

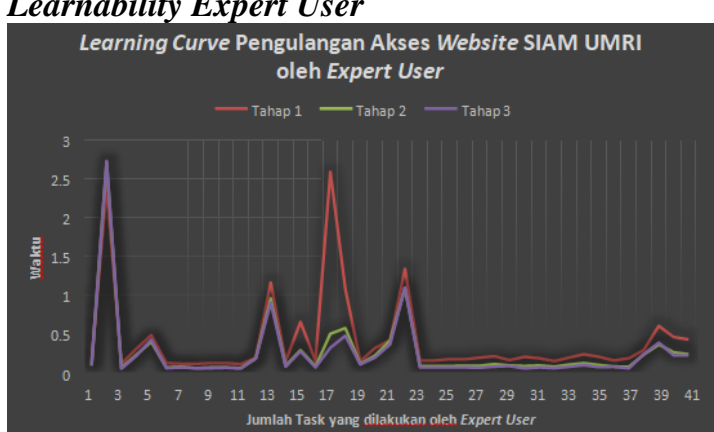

Gambar 13. Learning Curve Pengulangan Task oleh Expert User

\section{Learnability Novice User}

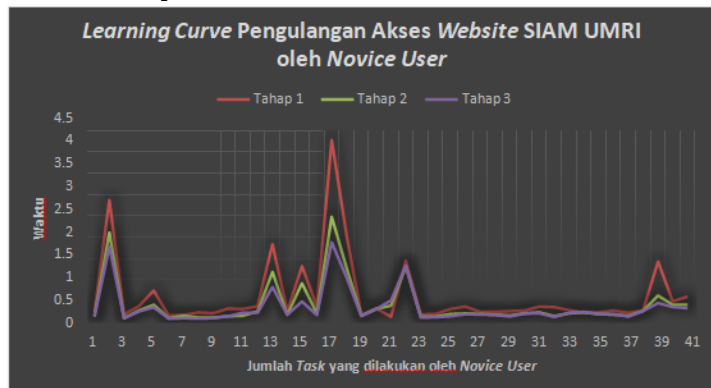

Gambar 14. Learning Curve Pengulangan Task oleh Novice User

Efficiency of Use Expert User

Tabel 6. Waktu Memorability Expert User dalam menyelesaikan 1 Task

\begin{tabular}{|l|c|c|}
\hline & $\begin{array}{c}\text { Rata - Rata } \\
\text { Waktu } \\
\text { Penyelesaian Task } \\
\text { sesuai waktu yang } \\
\text { diberikan (30 } \\
\text { menit) }\end{array}$ & $\begin{array}{c}\text { Waktu yang } \\
\text { Dibutuhkan } \\
\text { Responden dalam } \\
\text { menyelesaikan 1 } \\
\text { Task } \text { (menit) }\end{array}$ \\
\hline Waktu Pengulangan 1 & 16.38 & 0.40 \\
\hline Waktu Pengulangan 2 & 10.35 & 0.25 \\
\hline Waktu Pengulangan 3 & 9.51 & 0.23 \\
\hline
\end{tabular}

Efficiency of Use Novice User

Tabel 7. Waktu Memorability Novice User dalam menyelesaikan 1 Task

\begin{tabular}{|l|c|c|}
\hline & $\begin{array}{c}\text { Rata - Rata } \\
\text { Waktu } \\
\text { Penyelesaian Task } \\
\text { sesuai waktu yang } \\
\text { diberikan (30 } \\
\text { menit) }\end{array}$ & $\begin{array}{c}\text { Waktu yang } \\
\text { Dibutuhkan } \\
\text { Responden dalam } \\
\text { menyelesaikan 1 } \\
\text { Task (menit) }\end{array}$ \\
\hline Waktu Pengulangan 1 & 25.29 & 0.62 \\
\hline Waktu Pengulangan 2 & 17.04 & 0.42 \\
\hline Waktu Pengulangan 3 & 14.50 & 0.35 \\
\hline
\end{tabular}

\section{Simpulan}

Berdasarkan hasil analisis serta pembahasan pengolahan data pada bab yang telah dijelaskan sebelumnya, dapat diambil kesimpulan :

1. Terdapat 8 keluhan yang ditemui pengguna saat mengakses website SIAM UMRI yang didapatkan menggunakan kuesioner pra penelitian terhadap mahasiswa UMRI

2. Lima dimensi tingkat usabilitas website SIAM UMRI pada dimensi learnability memiliki kemampuan mempelajari website dengan baik. Pada dimensi efficiency didapatkan hasil peningkatan kecepatan penyelesaian task oleh responden. Dalam dimensi memorability responden memiliki kemampuan mengingat yang baik. Selanjutnya pada dimensi error didapatkan 38 permasalahan yang ditemui saat mengakses website SIAM UMRI, serta pada dimensi satisfaction didapatkan hasil kepuasaan responden saat mengakses website SIAM UMRI dengan score 70.

3. Terdapat 13 rekomendasi dari 6 usability problem (feedback, konsistensi, navigasi, redundancies, tata letak dan desain layar, user control) yang dapat digunakan untuk perbaikan website SIAM UMRI.

\section{Saran}

Penelitian selanjutnya dapat dikembangkan evaluasi usabilitas pada website SIAM UMRI dengan menggunakan metode user feedback, dimana responden yang digunakan lebih banyak lagi (100 orang). Dengan harapan, dengan menggunakan metode ini akan dapat diketahui perubahan kebutuhan dan pandangan pengguna dari website SIAM UMRI ini. Namun penggunaan metode ini membutuhkan organisasi khusus untuk menangani balasan dari penelitian yang dilakukan.

Alangkah lebih baiknya terdapat lembaga independen yang dapat mengeksekusi metode ini 
agar penilaian usabilitas terhadap website SIAM UMRI lebih objektif

\section{Daftar Pustaka}

[1]. Arief, M. Rudyanto. 2011. Pemrograman web Dinamis Menggunakan PHP \& Mysql. Yogyakarta: Andi Offset.

[2]. Bangor, A., Kortum, P. T., \& Miller, J. (2009). Determining what individual SUS. scores mean : Adding an adjective rating scale. Journal of usability studies, 14-123.

[3]. Chiew, T.K. dan Salim, S.S. 2003. "Webuse: Website Usability Evaluation Tool." Malaysian Journal of Computer Science, Vol. 16 No. 1. Page 47-57

[4]. Djarwanto, 2007, Mengenal Beberapa Uji Statistik dalam Penelitian, Edisi Kedua, Liberty, Yogyakarta.

[5]. Faizal, M., Adriyanto, A., R., Perancangan Ulang Antar Muka Website Sebagai Media Informasi Perguruan Tinggi Universitas Telkom, Serat Rupa Journal of Design, No.1 (2), Bandung, 2018, Issn. 54-66.

[6]. Falahah, Khoirida Aelani.2012. Pengukuran Usability System Menggunakan Use Questionnaire (Studi Kasus Aplikasi Perwalian Online STMIK “AMIK BANDUNG”, Jurnal SNATI, ISSN : $1907-5022$

[7]. Fitri, Lara Ismano 2019. Pengembangan Sistem Penelusuran Alumni (SATIN) dengan Analisis Usability Testing dan User Experience. [Tugas Akhir] : Pekanbaru (ID) : Universitas Islam Negeri Sultan Syarif Kasim.

[8]. Galizt, Wilbert. O.. 2002. The Essential Guide to User Interface Design. Wiley.

[9]. nternasional Standard, Ergonomics of Human-System Interaction, Human Centred Design for Interactive System, 2010, ISO 9241-210

[10]. Irsyad, M., Affandes, M., dan Candra, R., M., Interaksi Manusia dan Komputer, Fakultas Saintek UIN SUSKA dan CV. Mulia Indah Kemala, Pekanbaru, 2015. Khanum, M. A., dan Trivedi, M. C., 2012, Take Care: A Study on Usability Evaluation Methods for Children, International Journal of Advanced Researchin Computer Science, vol. 3, no. 2, pp. 101-105

[11]. Linguard, G., 1994, Usability Testing and System Evaluation: A Guide for Designing
Useful Computer Systems, Chapman \& Hall, London, dalam Wijayanti, E., 2012, Usabilitas Software Humancad Versi 1.2, Skripsi Jurusan Teknik Mesin dan Industri Universitas Gadjah Mada, Yogyakarta.

[12]. Miftakhurrohman, Mokhamad. 2014. Analisis Usability Website Universitas di Indonesia dengan Metode Pembobotan Entropi serta Metode Perankingan Topsis dan Kaitannya dengan Peringkat Rilis Webometrics. [Tugas Akhir]. Yogyakarta (ID) : Universitas Negeri Yogyakarta

[13]. Mulianda, I., 2012, Analisis Relevansi Metode Uji Usabilitas Performance Measurement dan Thinking Aloud dengan Objek Penelitian Sistem Operasi Android. Skripsi Jurusan Teknik Mesin dan Industri Universitas Gadjah Mada, Yogyakarta.

[14]. Montgomery, D.C. and Runger, G.C., 2003, Applied Statistics and Probability for Engineers, 3rd ed., John Wiley \& Sons, Inc., New York.

[15]. Nahdhatuzzahra., Budiman, Irwan., Nugrahadi, Dodon. T. 2016. Penerapan Usability Testing terhadap Sistem Informasi Penyebaran Penyakit Unggas, Kumpulan Jurnal Ilmu Komputer, Vol. 03, No. 02.

[16]. Nielsen, J., 1993, Usability Engineering, Academic Press, San Diego.

[17]. Nielsen, J., Lorangr, H. 2006. Prioritizing Web Usability. Pearson Education Publishing. North America

[18]. Orshella, Devy Dwi, dkk. 2014. Analisis Perbandingan Tingkat Usabilitas pada Produk (Webmail) (Gmail \& Hotmail). [Laporan Penelitian]. Yogyakarta : Universitas Gadjah Mada

[19]. P, Sukma Fitriawan. 2009. Perancangan Ulang Website Teknik Industri Universitas Sebelas Maret dengan Memperhatikan Aspek Usabilitas Menggunakan Metode Focus Group Discussion. [Tugas Akhir]. Surabaya (ID) : Universitas Sebelas Maret

[20]. Puspitasari, Melita. 2014. Analisis Pengaruh Jumlah Sampel pada Evaluasi Usabilitas Aplikasi Edukasi Anak - Anak. [Tugas Akhir]. Yogyakarta (ID) : Universitas Gadjah Mada.

[21]. Rahadi, D., R., Pengukuran Usability Sistem Menggunakan Use Questionnaire pada Aplikasi Android, Jurnal Sistem Informasi (JSI), No. 1 (6), Pelembang, 2014, Issn. 2085-1588 
[22]. Santoso, I., Interaksi Manusia dan Komputer, ANDI Yogyakarta, Yogyakarta, 2010.

[23]. Setiyaningsih, W. dan Kuswinardi, Y.W. 2010. Penelitian Empiris Peran Aesthetics pada Web Usability 1(3): 1-9
[24]. Sudarmawan., Ariyus, D., Interaksi Manusia dan Komputer, ANDI Yogyakarta, Yogyakarta, 2007

[25]. Thowfeek, M.H. \& Salam, M.N.A. 2014. Students' Assessment on the Usability of Elearning Websites 141 : 916 - 922. 